Jurnal

\title{
Chronic Mitral Regurgitation : Optimal time to Intervention
}

\author{
Estu Rudiktyo, Amiliana M. Soesanto
}

'Resident of Cardiology and Vascular Faculty of Medicine, Brawijaya University Malang 2Department of Cardiology and Vascular dr.Saiful Anwar General Hospital/Faculty of Medicine, Brawijaya University Malang
Chronic mitral regurgitation is commonly encountered valve disease. In this disease, there is volume overload on the left ventricle leading to left ventricle dilatation and dysfuction. Surgical or percutaneous intervention can improve prognosis, however optimal timing of intervention still controversial. In the past, timing of intervention was based solely on symptoms and left ventricle function. There have been recent advances in our knowledge, diagnosis, and treatment of mitral regurgitation. All of these advances have provided an incentive to change the indication for timing of operations in patients with mitral regurgitation, setting a new paradigm of an early operation before the onset of ventricular dysfunction. In this article we will outline these newer advances and provide recommendations regarding optimal timing of intervention for mitral regurgitation.

(J Kardiol Indones. 2015;36: I II-9)

Keywords: Primary mitral regurgitation, fuctional mitral regurgitation , timing of intervention, mitral valve surgery 
Jurnal

Kardiologi Indonesia

J Kardiol Indones. 2015;36:1 II-9

ISSN $0126 / 3773$

\title{
Tinjauan Pustaka
}

\section{Regurgitasi Mitral Kronik: Waktu Intervensi yang Optimal}

\author{
Estu Rudiktyo, Amiliana M. Soesanto
}

\begin{abstract}
Regurgitasi mitral kronik merupakan salah satu penyakit katup jantung yang sering dijumpai. Pada kelainan ini ditemukan beban volume yang berlebihan pada ventrikel kiri yang akhirnya berakibat pada dilatasi dan gangguan fungsi ventrikel kiri. Intervensi yang tepat akan dapat memperbaiki gangguan ini, akan tetapi waktu yang optimal untuk pembedahan pada pasien dengan regurgitasi mitral kronik berat masih menjadi kontroversi hingga saat ini. Pada masa lalu saat untuk melakukan intervensi bedah ditentukan oleh gejala dan gangguan fungsi ventrikel kiri, akan tetapi sejalan dengan berkembangnya pemahaman tentang patofisiologi regurgitasi mitral kronik dan semakin majunya teknik pembedahan, banyak studi yang melaporkan bahwa pembedahan yang dilakukan sebelum timbul gejala atau gangguan fungsi ventrikel kiri dapat memberikan prognosis lebih baik. Pada tinjauan pustaka ini akan dibahas lebih detail tentang waktu intervensi yang optimal pada regurgitasi mitral kronik yang ddidasarkan pada pemahaman terkini patofisiologi katup mitral dan kemajuan teknik pembedahan.
\end{abstract}

(J Kardiol Indones. 2015;36:111-9)

Kata kunci: Regurgitasi mitral primer, regurgitasi mitral fungsional, waktu intervensi, operasi katup mitral

\section{Pendahuluan}

Waktu optimal untuk intervensi pada pasien dengan regurgitasi mitral (RM) kronik berat masih kontroversi hingga saat ini. Intervensi untuk mengganti atau memperbaiki katup mitral dapat meningkatkan status fungsional pada pasien dengan gejala, sehingga

\section{Alamat Korespondensi}

dr. Estu Rudiktyo. 'Program Pendidikan Dokter Spesialis IImu Jantung dan Pembuluh Darah Fakultas Kedokteran Universitas Brawijaya Malang, ${ }^{2}$ Departemen IImu Penyakit Jantung dan Pembuluh Darah RS Umum Dr. Saiful Anwar/Fakultas Kedokteran Universitas Brawijaya Malang. E-mail: esturudi@gmail.com indikasi untuk intervensi terutama didasarkan pada ada atau tidaknya gejala tersebut. ${ }^{1-3}$ Beberapa studi terbaru melaporkan bahwa perjalanan alamiah RM kronik lebih berat dari yang diperkirakan sebelumnya dan dilaporkan pula bahwa intervensi pada pasien tanpa gejala dapat meningkatkan kesintasan (survival) dan mengurangi resiko gagal jantung serta fibrilasi atrium (AF). Pada masa lalu, dokter cenderung ragu untuk melakukan intervensi pada pasien tanpa gejala karena tingginya morbiditas dan mortalitas operasi serta kemungkinan komplikasi jangka panjang akibat penggunaan katup prostetik. 4,5

Kemajuan di bidang kardiologi telah memberikan 
pemahaman yang lebih baik terkait patofisiologi, diagnosis dan tatalaksana RM. Patofisiologi kelebihan cairan pada ventrikel kiri dan pengaruhnya pada disfungsi ventrikel saat ini sudah dipahami lebih jauh, begitu pula perjalanan alamiah RM. Teknologi dan parameter ekokardiografi terbaru sudah dapat menilai morfologi katup dan tingkat keparahan dengan lebih akurat. Semakin majunya teknik intervensi juga membuat mortalitas dan morbiditas intervensi lebih rendah dengan prognosis jangka panjang yang lebih baik. ${ }^{4,6}$

\section{Patofisiologi}

Terdapat beberapa tahap perubahan hemodinamik RM, yaitu tahap kelebihan volume akut, kompensasi kronik, transisi dan dekompensasi dengan disfungsi ventrikel yang menetap. ${ }^{1}$

\section{Tahap Kelebihan Volume Akut}

Pada tahap ini terdapat volume berlebih yang mendadak pada atrium dan ventrikel kiri yang mengakibatkan peningkatan akut tekanan di atrium kiri dan sirkulasi pulmonal. Kelebihan volume ini menimbulkan keluhan sesak napas berat dan seringkali disertai edema paru. Volume sekuncup dan curah jantung berkurang karena terdapat darah yang dialirkan kembali ke atrium kiri. Pada pasien dengan RM kronik yang bukan disebabkan oleh suatu penyebab akut, tahap ini tidak dijumpai. ${ }^{4}$

Respons jangka pendek adalah dengan meningkatkan volume ventrikel kiri sehingga volume sekuncup total meningkat melalui mekanisme Starling. Fractional shortening ventrikel kiri meningkat dan volume sistolik akhir menurun akibat resistensi atrium kiri yang rendah. Bila curah jantung dapat dipertahankan dengan mekanisme kompensasi ini, selanjutnya akan terjadi transisi dari tahap akut menjadi tahap kompensasi kronik. ${ }^{7}$

\section{Tahap Kompensasi Kronik}

Mekanisme kompensasi pada tahap ini adalah dilatasi ventrikel kiri. Dilatasi ventrikel terjadi melalui perubahan sarkomer otot jantung. Peningkatan ukuran ventrikel kiri memungkinkan lebih banyak volume darah yang ditampung sebagai akibat dari RM dengan tetap mempertahankan tekanan diastolik yang normal. ${ }^{7}$ Pasien cenderung tanpa gejala pada tahap ini karena curah jantung yang adekuat. Sebagian pasien dapat bertahan dalam tahap kompensasi kronik ini hingga puluhan tahun setelah onset RM. ${ }^{4,7}$

\section{Tahap Transisi}

Waktu timbulnya tahap transisi sulit ditentukan. Gejala tidak dapat dijadikan panduan akurat untuk menentukan waktu terjadinya transisi antara tahap kompensasi dan dekompensasi. Parameter ekokardiografi fraksi ejeksi (EF) tidak mencerminkan fungsi ventrikel yang sebenarnya karena sangat dipengaruhi oleh tingkat pengisian ventrikel. Parameter EF dan fractional shortening dapat tetap normal walaupun sudah terjadi penurunan fungsi ventrikel. Parameter ekokardiografi baru seperti preload corrected ejection fraction, end-systolic wall stress normalized for end-systolic volume index, mass normalization of left ventricular elastance, and end-systolic wall stress normalization of ejection fraction dilaporkan dapat menentukan tahap transisi dengan lebih akurat. ${ }^{8}$

\section{Tahap Dekompensasi dengan Disfungsi Ventrikel Kiri yang Menetap}

Pada perkembangan selanjutnya akan timbul dilatasi ventrikel kiri progresif. Dilatasi ini terjadi akibat peningkatan derajat keparahan RM dan berlanjutnya proses kompensasi atau kombinasi keduanya. Kompetensi katup mitral sangat ditentukan oleh fungsi seluruh komponen apparatus mitral yang mencakup annulus mitral, otot papilaris, korda dan leaflet. Dilatasi ventrikel sendiri dapat memperberat RM melalui perubahan geometri ventrikel dan dilatasi annulus mitral. Pada kasus degeneratif, gangguan pada struktur pendukung seperti ruptur korda dapat memperberat regurgitasi. Tekanan sistolik pada dinding ventrikel bertambah sejalan dengan progresifitas penyakit. Peningkatan tekanan abnormal ini mengakibatkan penurunan kontraktilitas yang diikuti penurunan jumlah massa otot jantung dan peningkatan jaringan ikat fibrosa. Bila proses ini berlanjut, disfungsi ventrikel akan menetap dengan prognosis yang buruk. ${ }^{4,9}$

\section{Kemajuan dalam Intervensi}

Kemajuan pesat intervensi katup mitral memberikan 
efek yang baik terhadap mortalitas dan prognosis jangka panjang. Penyebab paling sering RM di negara maju adalah penyakit katup degeneratif dengan mekanisme yang paling sering dijumpai berupa prolaps leaflet katup. Sekitar 95\% pasien dengan prolaps katup mitral dapat menjalani operasi perbaikan katup (mitral valve repair) tanpa disertai dengan penggantian katup. Teknik ini memiliki angka mortalitas operasi yang relatif rendah dan daya tahan katup yang hampir serupa dengan penggunaan katup prostetik. Sebuah studi melaporkan bahwa angka mortalitas operasi perbaikan katup mitral pada pasien berusia di bawah 75 tahun kurang dari $1 \%$ dengan resiko operasi ulang setiap tahunnya hanya sekitar $0.5 \%$. Studi lain melaporkan bahwa durabilitas katup mitral setelah menjalani operasi perbaikan serupa dengan katup prostetik (angka operasi ulang 0.74\%). ${ }^{10}$

Operasi perbaikan katup lebih dipilih dibanding penggantian katup karena angka mortalitas operasi yang rendah dan dapat menghindari resiko terkait katup prostetik seperti trombus. Korda dan struktur pendukung katup mitral lainnya tetap dipertahankan pada operasi perbaikan katup, sehingga membantu mempertahankan fungsi sistolik dan bentuk ventrikel kiri. Selain itu tampak pula kemajuan teknik operasi pada kelompok pasien yang harus menjalani operasi penggantian katup, yaitu penggantian katup mitral dengan tetap mempertahankan korda. Teknik ini dapat membantu mengurangi ukuran ventrikel pasca-operasi dan dan mencegah penurunan EF.4,10

Pembedahan merupakan baku emas intervensi pada kasus RM dari segi efektivitas, akan tetapi sebagian pasien memiliki komorbid yang akhirnya tidak menjalani operasi karena resikonya dianggap terlalu tinggi. Oleh karena itu dikembangkan teknik intervensi RM perkutan yang dianggap memiliki resiko prosedur lebih rendah. Salah satu teknik yang dikembangkan adalah Mitral Clip (Gambar 1). Prosedur ini bertujuan untuk memperbaiki katup mitral tanpa menggunakan mesin pintas kardiopulmoner dengan segala resikonya. Beberapa studi seperti EVEREST I dan EVEREST II telah melaporkan keamanan dan efektivitas teknik ini. Tingkat keberhasilan tindakan mencapai 74\%. ${ }^{11}{ }^{12}$

\section{Waktu Pembedahan Regurgitasi Mitral Primer}

Waktu pembedahan yang optimal pada pasien dengan RM primer ditentukan oleh berbagai faktor, mencakup keluhan, derajat keparahan regurgitasi dan respons ventrikel kiri terhadap kelebihan volume. ${ }^{1}$ Faktor lainnya yang sangat berperan adalah fasilitas intervensi. Kemampuan untuk memperbaiki katup mitral dibandingkan melakukan operasi penggantian katup menjadi salah satu pertimbangan utama untuk melakukan operasi lebih dini. ${ }^{10}$ Jumlah pasien yang mengalami operasi perbaikan katup meningkat drastis dalam beberapa waktu terakhir, akan tetapi dilaporkan teknik ini masih dibawah dari angka yang diharapkan yaitu berkisar 35.7\% berdasarkan data yang dilaporkan oleh Society of Thoracic Surgeons. 4,13

Angka ini sangat berbeda dengan jumlah operasi perbaikan katup yang dilakukan oleh beberapa institusi atau rumah sakit yang sangat berpengalaman dalam melakukan teknik operasi tersebut, yakni antara 9095\% dari seluruh pasien katup mitral degeneratif. Operasi perbaikan memiliki angka mortalitas yang lebih rendah dibandingkan dengan penggantian katup (1-2\% vs 6\%), preservasi fungsi ventrikel kiri dan kesintasan yang lebih baik, oleh karena itu diharapkan dokter ahli jantung dan timnya lebih memilih operasi perbaikan katup mitral. ${ }^{10}$

\section{Pasien dengan gejala dan fungsi ventrikel kiri yang normal}

Banyak studi yang melaporkan bahwa pasien RM berat disertai gejala (NYHA kelas III atau IV) dengan fungsi ventrikel kiri masih normal akan mendapatkan manfaat dari intervensi. Fungsi ventrikel yang normal didefinisikan sebagai fraksi ejeksi lebih dari $60 \%$ dan dimensi sistolik akhir kurang dari $40 \mathrm{~mm}$ berdasarkan ekokardiografi. Manfaat yang dimaksud adalah membaiknya kelas fungsional dan meningkatkan kesintasan. Pasien dengan gejala ringan (NYHA kelas II) juga harus dipertimbangkan untuk menjalani pembedahan. Gejala yang timbul, walaupun ringan, menandakan bahwa pasien sudah memasuki tahap transisi dekompensasi ventrikel kiri, tahap di mana mekanisme kompensasi sudah mulai tidak bisa mengatasi volume yang berlebih, sehingga pasien dengan regurgitasi mitral berat primer disertai gejala yang terkait (NYHA II-IV) harus dipertimbangkan untuk menjalani pembedahan. ${ }^{1,14}$

\section{Pasien dengan Gangguan Fungsi Ventrikel Kiri}

Pembedahan katup mitral diindikasikan pada pasien 
dengan RM berat primer yang disertai gangguan fungsi ventrikel kiri, baik pada pasien yang disertai gejala maupun yang tanpa gejala. Kelompok pasien ini telah mengalami progresifitas penyakit menuju tahap disfungsi ventrikel yang menetap akibat kelebihan volume yang berlangsung kronik, oleh karena itu sebenarnya lebih diharapkan jika pasien sudah menjalani pembedahan sebelum memasuki tahap ini. Pada kelompok pasien ini dapat dilakukan perbaikan atau penggantian katup mitral tergantung kondisi katup dan fasilitas yang ada walaupun perbaikan katup umumnya lebih diutamakan. ${ }^{1,4}$

\section{Pasien dengan Gejala dan Gangguan Ventrikel Kiri Berat}

Sebagian pasien datang dengan regurgitasi mitral berat dalam kondisi yang dapat dianggap sebagai RM tahap akhir (end-stage), yaitu dengan penurunan fungsi ventrikel yang sangat berat (ejeksi fraksi kurang dari 30\% atau dimensi sistolik akhir lebih dari $55 \mathrm{~mm}$ ). Pada kelompok pasien ini resiko operasi lebih tinggi dibandingkan kelompok lainnya dan kemungkinan menetapnya gangguan fungsi ventrikel kiri setelah operasi sangat tinggi. Pembedahan tetap dapat dilakukan pada kelompok pasien ini setelah mempertimbangkan dengan baik untung dan ruginya, dan bila diputuskan operasi, maka operasi perbaikan katup lebih diutamakan. ${ }^{4}$

\section{Pasien tanpa Gejala dengan Fungsi Ventrikel Normal}

Tatalaksana pasien regurgitasi mitral berat akibat kelainan katup mitral primer tanpa gejala dengan fungsi sistolik yang normal masih menjadi kontroversi. Jika pada kelompok pasien ini waktu operasi ditunda hingga timbul gangguan ventrikel kiri, maka pasien telah masuk tahap dekompensasi dan gangguan fungsi ventrikel diperkirakan akan menetap. Morbiditas dan mortalitas pasca operasi akan lebih tinggi bila telah timbul gangguan fungsi ventrikel sebelum operasi. Oleh karena itu beberapa institusi menyarankan pasien menjalani pembedahan sebelum timbul gangguan fungsi ventrikel kiri. ${ }^{1,2,7}$

Pada beberapa institusi, ada kecenderungan untuk melakukan operasi pada kelompok pasien ini bila kemungkinan keberhasilan operasi perbaikan sangat tinggi dengan resiko yang rendah. Pada institusi yang baik, angka keberhasilan perbaikan katup mitral mencapai lebih dari 90\% dengan mortalitas kurang dari $1 \%$. Perubahan paradigma untuk operasi lebih dini berkembang sejalan bertambahnya pemahaman seputar patofisiologi RM. Prognosis jangka panjang kelompok pasien yang menjalani pembedahan dini ini sangat baik, hampir serupa dengan prognosis populasi normal. ${ }^{2,4}$

Sebelum merekomendasikan operasi pada kelompok ini, ada beberapa hal yang perlu dipastikan. Pertama, harus didokumentasikan dengan akurat bahwa RM benar-benar sudah termasuk yang berat. Selanjutnya perlu diketahui juga efek RM dengan ventrikel kiri dan atrium kiri, pasien dengan RM yang berat umumnya telah disertai pembesaran ventrikel dam atrium kiri. Terakhir, yang perlu juga diperhatikan adalah feasibilitas perbaikan katup dan ketersediaan institusi yang berpengalaman. Bila tidak ada institusi yang berpengalaman dalam perbaikan katup mitral, operasi dini sebaiknya tidak direkomendasikan pada pasien. ${ }^{4}$

\section{Fibrilasi Atrium}

Pasien RM memiliki resiko mengalami AF. AF sebelum operasi merupakan prediktor independen penurunan kesintasan jangka panjang setelah operasi katup mitral. Prediktor menetapnya AF pasca operasi adalah dilatasi atrium kiri dan durasi AF pre-operasi, terutama yang sudah berlangsung lebih dari 3 bulan. Operasi diindikasikan bila pada pasien RM telah timbul AF untuk mencegah efek yang tidak diinginkan dari AF tersebut. Pada pasien yang memang sudah memiliki AF, perlu dipertimbangkan dilakukan maze procedure atau isolasi vena pulmonal saat operasi katup. ${ }^{15,16}$

\section{Waktu Pembedahan Regurgitasi Mitral Iskemik}

Sebagian pasien dengan penyakit jantung iskemik dapat mengalami RM dan keberadaan regurgitasi mitral ini dilaporkan memiliki efek yang kurang baik terhadap prognosis. Sekitar $40 \%$ pasien dengan infark miokard akut didapatkan RM iskemik pada berbagai derajat keparahan dari yang ringan hingga berat. Resiko kejadian kardiovaskular yang tidak diinginkan pada kelompok yang disertai regurgitasi yang ringan sekalipun ternyata mencapai 2 hingga 4 kali lipat dibandingkan kelompok yang tidak memiliki RM iskemik. Semakin berat derajat regurgitasi maka akan 
semakin buruk kesintasan. Pada populasi pasien yang menjalani bedah pintas arteri koroner, dilaporkan satu dari sepuluh pasien memiliki RM iskemik dan pasien-pasien tersebut memiliki mortalitas operasi yang lebih tinggi dan kesintasan jangka panjang yang lebih rendah. ${ }^{17,18}$

Revaskularisasi dapat memperbaiki RM iskemik pada sebagian pasien, karena RM timbul akibat iskemia yang mengganggu kerja struktur pendukung katup mitral. Sayang sekali, sangat sulit untuk menentukan apakah dengan hanya dengan dilakukannya revaskularisasi akan memperbaiki RM pada semua pasien. Pada masa lalu, melakukan bedah pintas arteri koroner disertai dengan perbaikan atau penggantian katup mitral dianggap akan melipatgandakan resiko operasi, akan tetapi beberapa studi yang lebih baru melaporkan angka mortalitas lebih rendah dari yang diperkirakan sebelumya. Oleh karena itu, bila operasi bedah pintas arteri koroner juga disertai operasi katup mitral, perbaikan katup mitral lebih diutamakan dibanding penggantian katup, walaupun masih terdapat kontroversi terkait manfaat operasi katup mitral bersama dengan bedah pintas arteri koroner bila dibandingkan dengan BPAK saja. ${ }^{17,18}$

Waktu untuk dilakukannya pembedahan pada kasus regurgitasi mitral iskemik juga masih kontroversial hingga saat ini. Sebagian besar ahli sepakat bahwa RM berat berdasarkan temuan ekokardiografi atau ventrikulografi merupakan indikasi untuk dilakukan intervensi saat operasi BPAK, sedangkan pada pasien dengan RM iskemik yang ringan juga telah diketahui tidak akan mendapat manfaat dari operasi katup mitral. Perbedaan timbul pada kasus RM iskemik dengan derajat keparahan yang sedang. Hingga saat ini belum ada studi prospektif yang meneliti populasi ini, studi-studi terdahulu umumnya bersifat retrospektif dengan bias seleksi yang bermakna sehingga hasilnya kurang dapat dijadikan acuan. ${ }^{4}$



Gambar 1. Tatalaksana RM kronik menurut ACC/AHA. ${ }^{20}$ 


\section{Waktu Pembedahan Regurgitasi Mitral Fungsional}

Regurgitasi mitral fungsional timbul akibat dilatasi progresif ventrikel kiri yang diikuti dilatasi anulus mitral dan gangguan koaptasi leaflet. Tingkat keparahan regurgitasi mitral tergantung dari pengisian jantung sehingga terapi medikamentosa agresif untuk mengurangi volume ventrikel dapat mengurangi derajat regurgitasi mitral. Sebagian pasien dilaporkan tetap mengalami regurgitasi mitral yang berat walaupun sudah mendapat terapi yang optimal. Pada populasi ini, terdapat penurunan efisiensi kontraktilitas ventrikel kiri, sehingga diharapkan bila efisiensi ventrikel kiri ditingkatkan dengan menghilangkan volume regurgitasi melalui intervensi, maka fungsi ventrikel kiri akan membaik. ${ }^{4,19}$

Perbaikan katup mitral dilaporkan yang relatif aman pada populasi pasien resiko tinggi ini yang terdiri dari pasien-pasien dengan regurgitasi mitral fungsional berat, kelas fungsional II-IV, fraksi ejeksi kurang dari $35 \%$ dan dilatasi ventrikel kiri. Mortalitas operasi dilaporkan berkisar antara $1.5-5 \%$ pada satu institusi. Operasi perbaikan katup mitral dapat memperbaiki kelas fungsional pada populasi ini berikut perbaikan ejeksi fraksi, curah jantung dan volume diastolik akhir. Akan tetapi, manfaat ini tidak tampak pada studi lain, sehingga hingga saat ini indikasi operasi pada populasi ini belum jelas. Hingga informasi lebih lengkap tersedia, terapi medikamentosa agresif, termasuk penggunaan pacu jantung biventrikel dianggap merupakan lini pertama pada pasien disfungsi ventrikel kiri yang berat dan dengan regurgitasi mitral fungsional. Operasi merupakan alternatif terakhir pada pasien yang tetap mengeluhkan gejala walaupun sudah mendapatkan terapi medikamentosa optimal. ${ }^{4,19}$

\section{Waktu Intervensi berdasarkan Guidelines}

Saat ini terdapat dua panduan diagnosis dan tatalaksana penyakit katup jantung yang umum digunakan yakni dari ESC (2012) dan ACC/AHA (2014). Secara umum kedua panduan ini memliki banyak kemiripan dalam merekomendasikan intervensi pada RM kronik. Keduanya merekomendasikan pembedahan pada pasien dengan gejala dan $\mathrm{EF}>30 \%$ dan pada pasien tanpa gejala tapi dengan penurunan $\mathrm{EF}(\mathrm{EF}<60 \%)$. Operasi perbaikan katup bila memungkinkan juga

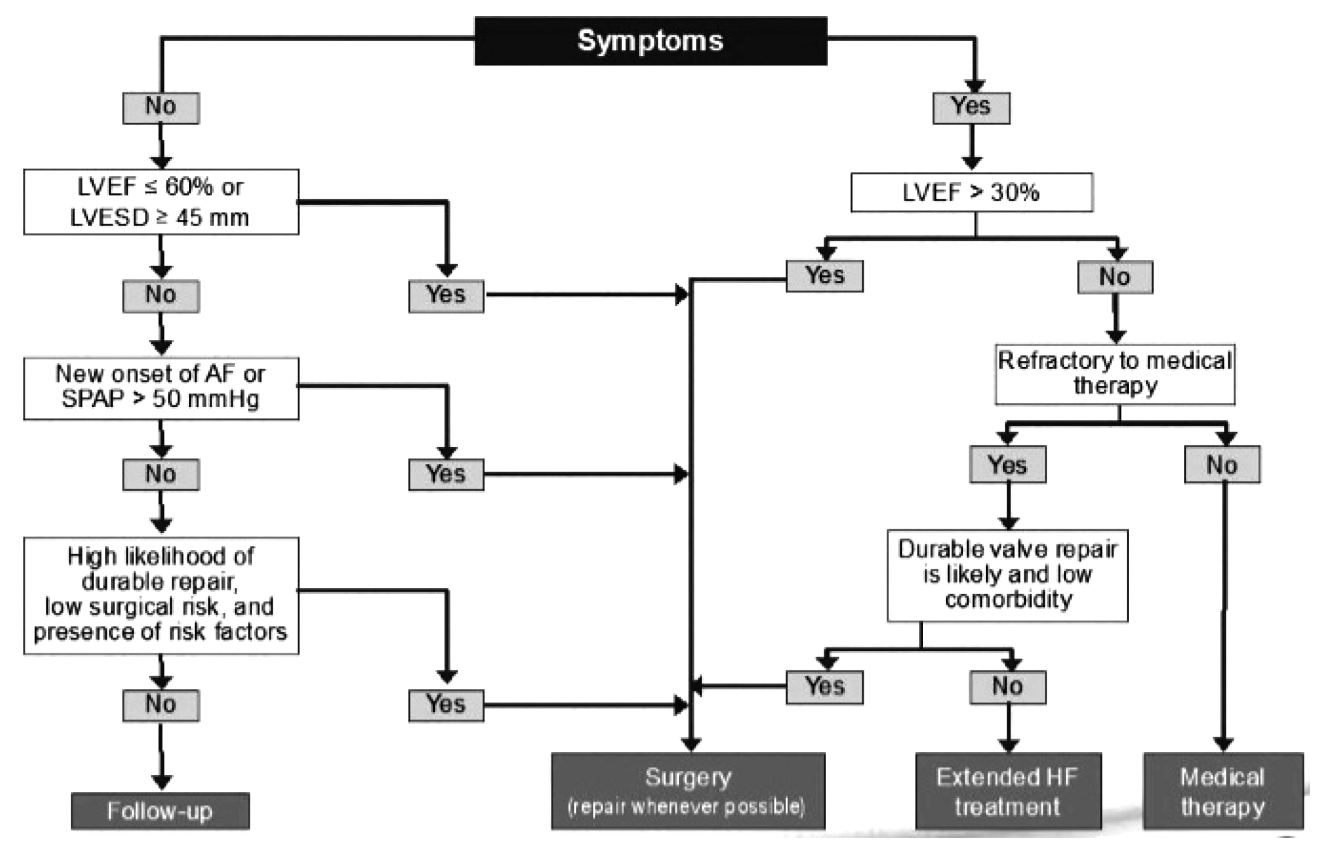

Gambar 2. Tatalaksana RM kronik primer menurut ESC. ${ }^{21}$ 
lebih dianjurkan oleh keduanya. ESC dan ACC/AHA berbeda dalam hal intervensi katup mitral perkutan, ACC/AHA merekomendasikan teknik perbaikan katup mitral perkutan pada populasi resiko tinggi operasi. ESC tidak mencantumkan rekomendasi ini dalam panduannya. Rekomendasi ESC dan ACC/ AHA dapat dilihat pada Gambar 1 dan 2.20,21

\section{Ringkasan}

Waktu operasi yang optimal pada pasien regurgitasi mitral masih menjadi topik yang kontroversial, akan tetapi sejalan dengan berkembangnya pemahaman terkait patofisiologi dan perjalanan alamiah penyakit ini, serta makin baiknya teknik intervensi, telah membuat banyak kemajuan dalam tatalaksana pasien dengan regurgitasi mitral. Beberapa hal yang perlu dipertimbangkan sebelum memutuskan waktu pembedahan pada pasien dengan regurgitasi mitral adalah etiologi penyakit, tingkat keparahan regurgitasi, fungsi ventrikel kiri dan fibrilasi atrium, ada atau tidaknya gejala serta penyakit penyerta yang ada seperti penyakit jantung koroner, serta ketersediaan fasilitas kesehatan yang memadai. Melakukan intervensi di saat yang tepat diharapkan dapat memperbaiki prognosis pasien.

\section{Daftar Pustaka}

1. Bonow RO, Carabello BA, Chatterjee K, et al. 2008 focused update incorporated into the ACC/AHA 2006 guidelines for the management of patients with valvular heart disease: a report of the American College of Cardiology/American Heart Association Task Force on Practice Guidelines (Writing Committee to revise the 1998 guidelines for the management of patients with valvular heart disease). Endorsed by the Society of Cardiovascular Anesthesiologists, Society for Cardiovascular Angiography and Interventions, and Society of Thoracic Surgeons. J Am Coll Cardiol. Sep 23 2008;52(13):e1-142.

2. Enriquez-Sarano M, Orszulak TA, Schaff HV, Abel MD, Tajik AJ, Frye RL. Mitral regurgitation: a new clinical perspective. Mayo Clin Proc. Nov 1997;72(11):1034-43.

3. Fowler NO, van der Bel-Kahn JM. Indications for surgical replacement of the mitral valve. With particular reference to common and uncommon causes of mitral regurgitation. $\mathrm{Am} \mathrm{J}$ Cardiol. Jul 1979;44(1):148-57.

4. Nishimura R, Schaff HV. Mitral Regurgitation: Timing of Surgery. In: Bonow RO, Otto CM, eds. Valvular heart disease : a companion to Braunwald's heart disease. Fourth edition. ed.
Philadelphia: Saunders; 2009:p.

5. Enriquez-Sarano M, Schaff HV, Frye RL. Early surgery for mitral regurgitation: the advantages of youth. Circulation. Dec 16 1997;96(12):4121-3.

6. Ling LH, Enriquez-Sarano M, Seward JB, et al. Clinical outcome of mitral regurgitation due to flail leaflet. $N$ Engl J Med. Nov 7 1996;335(19):1417-23.

7. Gaasch WH, John RM, Aurigemma GP. Managing asymptomatic patients with chronic mitral regurgitation. Chest. Sep 1995;108(3):842-7.

8. Gaasch WH, Zile MR. Left ventricular function after surgical correction of chronic mitral regurgitation. Eur Heart J. Jul 1991;12 Suppl B:48-51.

9. Ross J, Jr. The timing of surgery for severe mitral regurgitation. N Engl J Med. Nov 7 1996;335(19):1456-8.

10. Schaff HV, Suri RM, Enriquez-Sarano M. Indications for surgery in degenerative mitral valve disease. Semin Thorac Cardiovasc Surg. Summer 2007;19(2):97-102.

11. Tamburino C, Ussia GP, Maisano F, et al. Percutaneous mitral valve repair with the MitraClip system: acute results from a real world setting. Eur Heart J. Jun 2010;31(11):1382-9.

12. Feldman T, Kar S, Rinaldi M, et al. Percutaneous mitral repair with the MitraClip system: safety and midterm durability in the initial EVEREST (Endovascular Valve Edge-to-Edge REpair Study) cohort. J Am Coll Cardiol. Aug 18 2009;54(8):686-94.

13. Savage EB, Ferguson TB, Jr., DiSesa VJ. Use of mitral valve repair: analysis of contemporary United States experience reported to the Society of Thoracic Surgeons National Cardiac Database. Ann Thorac Surg. Mar 2003;75(3):820-5.

14. Tribouilloy CM, Enriquez-Sarano M, Schaff HV, et al. Impact of preoperative symptoms on survival after surgical correction of organic mitral regurgitation: rationale for optimizing surgical indications. Circulation. Jan 26 1999;99(3):400-5.

15. Chua YL, Schaff HV, Orszulak TA, Morris JJ. Outcome of mitral valve repair in patients with preoperative atrial fibrillation. Should the maze procedure be combined with mitral valvuloplasty? J Thorac Cardiovasc Surg. Feb 1994;107(2):408-15.

16. Grigioni F, Avierinos JF, Ling LH, et al. Atrial fibrillation complicating the course of degenerative mitral regurgitation: determinants and long-term outcome. J Am Coll Cardiol. Jul 3 2002;40(1):84-92.

17. Dion R. Ischemic mitral regurgitation: when and how should it be corrected? J Heart Valve Dis. Sep 1993;2(5):536-43.

18. Grigioni F, Enriquez-Sarano M, Zehr KJ, Bailey KR, Tajik AJ. Ischemic mitral regurgitation: long-term outcome and prognostic implications with quantitative Doppler assessment. Circulation. Apr 3 2001;103(13):1759-64.

19. Grossi EA, Crooke GA. Mitral valve surgery in heart failure: insights from the Acorn clinical trial. J Thorac Cardiovasc Surg. Sep 2006;132(3):455-6. 


\section{Rudiktyo E dkk: Regurgitasi Mitral Kronik: Waktu Intervensi yang Optimal}

20. Nishimura RA, Otto CM, Bonow RO, et al. 2014 AHA/ACC Guideline for the Management of Patients With Valvular Heart Disease: A Report of the American College of Cardiology/ American Heart Association Task Force on Practice Guidelines.
Circulation. Mar 32014.

21. Vahanian A, Alfieri O, Andreotti F, et al. Guidelines on the management of valvular heart disease (version 2012). Eur Heart J. Oct 2012;33(19):2451-96. 